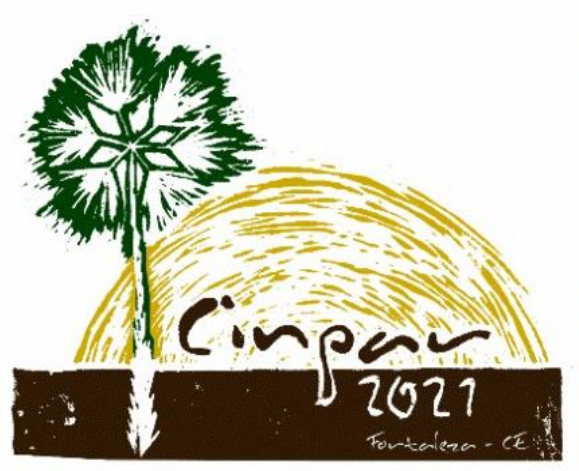

XVII Congresso Internacional sobre Patologia e

Reabilitação das Construções

XVII Congreso Internacional sobre Patología y Rehabilitación de las Construcciones

XVII International Conference on Pathology and Constructions Rehabilitation

FORTALEZA (Brasil), 3 a 5 de junho de 2021

https://doi.org/10.4322/CINPAR.2021.026

\title{
Análise da infuência do uso do metacaulim de alta reatividade (MAR) nas propriedades mecânicas de concretos autoadensáveis (CAA)
}

\section{Analysis of the influence of the use of high reactivity metakaolin (MAR) on the mechanical properties of self-compacting concretes (CAA)}

\author{
Lucas Felipe DASSOLER ${ }^{1}$, Marinês LANGOSKI ${ }^{2}$, Rafaela Fontana CASANOVA ${ }^{3}$ \\ ${ }^{1}$ Universidade Regional Integrada, URI, Erechim, RS, Brasil, lucasdassoler04@gmail.com \\ ${ }^{2}$ Universidade Regional Integrada, URI, Erechim, RS, Brasil, engenheiraml@hotmail.com \\ ${ }^{3}$ Escola Politécnica de Engenharia Civil, IMED, Passo Fundo, RS, Brasil, rafaelafcasanova@hotmail.com
}

\begin{abstract}
Resumo: As adições minerais são empregadas no concreto com o objetivo de melhorar algumas de suas propriedades mecânicas, bem como, a sua durabilidade. Atualmente, tem-se difundido o uso de pozolanas de alta reatividade como matéria-prima para obtenção de concreto com menor consumo de cimento. 0 presente trabalho avaliou a influência de diferentes teores de metacaulim de alta reatividade em substituição à massa de cimento e a influência de diferentes tipos de cura na determinação das propriedades do concreto autoadensável, sendo elas, absorção de água e resistência à compressão. Os ensaios foram realizados nas idades de 28 e 63 dias. Na execução deste trabalho foram comparados concretos referência (sem adição de metacaulim), com concretos com adição de $10 \%$ de metacaulim de alta reatividade. Constatou-se uma diminuição da absorção de água por capilaridade para os ensaios realizados aos 63 dias, principalmente para os corpos de prova que passaram pelo processo de cura úmida. Quanto a resistência à compressão uniaxial observou-se um pequeno decréscimo nos concretos que possuíam $10 \%$ de metacaulim em sua composição, mas que não comprometeram os resultados, demonstrando-se dentro do esperado. Analisando o efeito isolado da cura úmida constatou-se um aumento considerável da resistência, assim como, a idade de execução dos ensaios que, aos 63 dias, em ambas as substituições promoveu um acréscimo considerável da resistência comparando-se com os ensaios realizados aos 28 dias. Com relação a variável substituição, não se obteve valores significativos nos ensaios realizados aos 63 dias, mas houve um considerável aumento do módulo de elasticidade no processo de cura exposta para 10\% de substituição dos ensaios realizados aos 28 dias. Contudo, é possível concluir que a utilização do MAR em substituição parcial do cimento Portland proporciona um menor consumo de cimento, sem alterar consideravelmente as propriedades físicas do concreto auto adensável.
\end{abstract}

Palavras-chave: Adições minerais, pozolanas, metacaulim de alta reatividade, concreto autoadensável.

Abstract: Mineral additions are used in concrete in order to improve some of its mechanical properties, as well as its durability. Currently, the use of highly reactive pozzolans has become widespread as a raw material for obtaining concrete with less cement consumption. The present work evaluated the influence of different levels of high reactivity metakaolin to replace the cement mass and the influence of different types of curing in determining the properties of self-compacting concrete, namely, water absorption and compressive strength. The tests were performed at the ages of 28 and 63 days. In carrying out this work, reference concretes (without addition of metakaolin) were compared with concretes with the addition of $10 \%$ high reactivity metakaolin. There was a decrease in the absorption of water by capillarity for the tests carried out at 63 days, mainly for the specimens that went through the process of wet curing. Regarding the resistance to uniaxial compression, a small decrease was observed in concretes that had $10 \%$ metakaolin in their 
composition, but which did not compromise the results, showing themselves as expected. Analyzing the isolated effect of wet curing, there was a considerable increase in resistance, as well as the age of running the tests, which at 63 days, in both substitutions promoted a considerable increase in resistance compared to the tests performed at 28 days. Regarding the substitution variable, no significant values were obtained in the tests performed at 63 days, but there was a considerable increase in the elasticity module in the curing process exposed to $10 \%$ replacement of the tests performed at 28 days. However, it is possible to conclude that the use of MAR in partial replacement of Portland cement provides a lower consumption of cement, without significantly altering the physical properties of self-compacting concrete.

Keywords: Mineral additives, pozzolans, high reactivity metakaolin, self-compacting concrete.

\section{Introdução}

O concreto é o material de construção civil mais utilizado em todo o mundo. Com isso aumentou a necessidade de se produzir mais cimento, ocasionando problemas ambientais em todo o mundo (LACERDA; HELENE, 2005). Só no Brasil, o consumo de cimento em 2018 ultrapassou os 72 milhões de toneladas, gerando assim, uma elevada emissão de $\mathrm{CO}_{2}$. Devido a esse fato, há uma busca constante de melhorias em suas propriedades para aumentar sua eficiência, reduzir o consumo de seus materiais constituintes, proporcionando assim, um grande ganho ecológico com a redução da quantidade de clínquer da produção do cimento.

De acordo com Duarte et al. (2017), nos últimos anos verificou-se um grande avanço em relação ao desempenho da tecnologia do concreto. Isto foi possível graças ao advento dos aditivos químicos, que possibilitaram atingir propriedades nunca antes alcançadas. Além disso, a introdução das adições minerais ao cimento e ao concreto também foi preponderante para o desenvolvimento da tecnologia do concreto moderno, principalmente no que se refere à durabilidade das estruturas de concreto.

De acordo com Lacerda e Helene (2005), o metacaulim de alta reatividade se tornou uma nova opção de material pozolânico. Embora seja utilizado em outros países a mais de 10 anos, trata-se de um material cuja a produção no Brasil iniciou-se no ano de 2002. O objetivo geral da presente pesquisa é verificar a influência da utilização do (MAR) em substituição parcial do cimento Portland nas propriedades mecânicas de concretos autoadensáveis (CAA).

\section{Referencial Teórico}

\subsection{Concreto auto adensável (CAA)}

O concreto auto adensável também conhecido pela sigla CAA, teve seu início em 1986, por meio de pesquisas realizadas na Universidade de Tokyo, no Japão. $O$ intuito dos pesquisadores era criar um material que apresentasse melhores desempenhos tanto na qualidade e como também na durabilidade das estruturas de concreto (GOMES, 2002). Apresenta como característica principal a capacidade de preencher os vazios e se auto adensar apenas com o efeito da gravidade e a sua fluidez. A auto adensamento do material é obtido por meio do equilibrio entre fluidez, a viscosidade moderada e a baixa coesão entre as partículas do concreto em seu estado fresco (EFNARC, 2002).

Além das características já citadas, o CAA possibilita vantagens, sendo elas diretas ou indiretas. Pode-se destacar como vantagens: a rapidez para concretagem, redução da mão-de-obra no canteiro e o acabamento com melhor qualidade. Outro ponto positivo do CAA é o fato de permitir a concretagem de grande dimensões e dispensar o processo de vibração do concreto, reduzindo o custo final da obra (COPPOLA, 2000).

Para Bosiljkov (2003) a adição de materiais finos no CAA melhora diversas propriedades, sendo estas no estado fresco ou também endurecido. $O$ aumento de partículas finas melhora a densidade do material, desta forma dificultando a percolação de agentes externos agressivos em seu interior. 
O metacaulim de alta reatividade, segundo Gardolinski et al. (2001), pode ser considerado uma pozolana de alto desempenho, sendo este um material cerâmico sintético com níveis de pureza elevado, devido ao seu processo de calcinação controlado. A caulinita é constituída basicamente por silicato de alumínio hidratado que apresenta em fase amorfa. A NBR 12653 (ABNT, 2014) classifica este material como uma pozolana tipo $\mathrm{N}$, que são pozolanas naturais ou artificiais.

De acordo com a NBR 15894 - 1 (ABNT, 2010), a interação física e química que ocorre com cimento modifica a reologia dos compósitos do concreto no estado fresco, melhorando a sua duralidade e o seu desempenho mecânico. A adição de metacaulim na composição da pasta cimentícia faz com que o mesmo ocupe os espaços dos vazios, promovendo a diminuição dos poros, além de auxiliar na melhoria da trabalhabilidade no estado fresco do concreto. O processo de hidratação do cimento Portland é acelerado com a adição de metacaulim, que atua como filler, reagindo com o $\mathrm{Ca}(\mathrm{OH})_{2}$ gerando silicato de cálcio hidratado $(\mathrm{C}-\mathrm{S}-$ $H$ ) adicional, garantindo assim propriedades especiais como aumento da resistência à compressão e à flexão, redução da porosidade e permeabilidade, aumento da resistência a sulfatos, resistência à difusibilidade de íons cloreto e mitigação da reação álcali-agregado. Com o conhecimento teórico proporcionado pelo levantamento bibliográfico citado realizou-se este trabalho, com a finalidade de avaliar as propriedades físicas e mecânicas do CAA com substituição parcial do cimento Portland por MAR, onde analisou-se a influência de diversos fatores nas variáveis de resposta, como tipo de cura, idade e substituição, com o intuito de chegar no melhor resultado possível.

\section{Metodologia de pesquisa}

A metodologia desta pesquisa procura demonstrar as propriedades dos materiais através de resultados obtidos na caracterização física, química e mecânica e procedimentos utilizados para a execução dos ensaios do programa experimental. A caracterização dos materiais e os ensaios foram executados no Laboratório de Preparo de Amostras e Técnicas Construtivas (LAPATEC), do curso de Engenharia Civil, da URI - Campus de Erechim e no Laboratório de Precisão Analítica, da URI - Campus de Erechim.

Para o conhecimento do desempenho do CAA, foi realizado este programa experimental constituído das seguintes etapas: seleção e caracterização dos materiais disponíveis para a produção do CAA, definição do processo de dosagem e betonadas e realização dos ensaios com concreto fresco e endurecido e a análise dos resultados.

\section{Resultados}

De modo a facilitar a compreensão e o entendimento, bem como, auxiliar o tratamento dos dados criou-se combinações de variáveis demonstradas na Quadro 1.

Quadro 1 - Combinações de variáveis.

\begin{tabular}{|c|c|c|}
\hline Tipo de cura & Teor de substituição \% & Combinação \\
\hline Exposta & 0 & C1 \\
\hline Exposta & 10 & C2 \\
\hline Úmida & 0 & C3 \\
\hline Úmida & 10 & C4 \\
\hline
\end{tabular}

Fonte: Autores (2020).

4.1 Absorção de água por capilaridade 
Os ensaios de absorção de água por capilaridade foram executados de acordo com a NBR 9779 (ABNT, 2012). As Figuras 1 e 2 demonstram os gráficos dos resultados de absorção de água por capilaridade seguindo a metodologia de tempo proposta na norma (3, 6, 24, 48 e 72 horas). Para cada combinação (C1, C2, C3 e C4) foram ensaiados $4 \mathrm{CPs}$. Os gráficos tem como objetivo comparar a influência optida em função dos teores de substituição (0 e 10\%) e do tipo de cura (úmida e exposta).

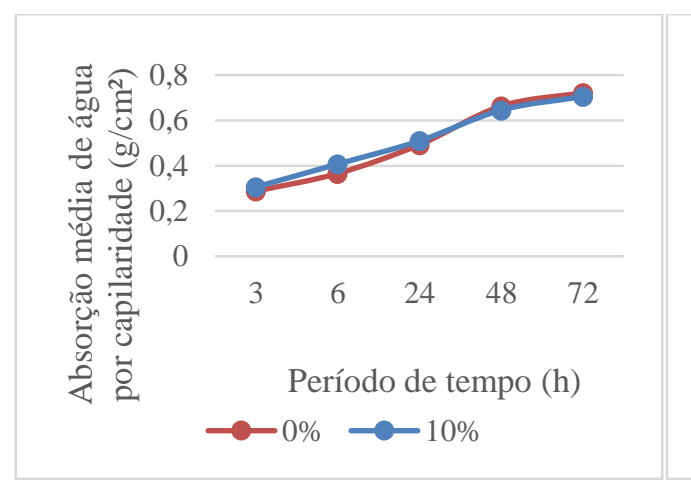

(a)

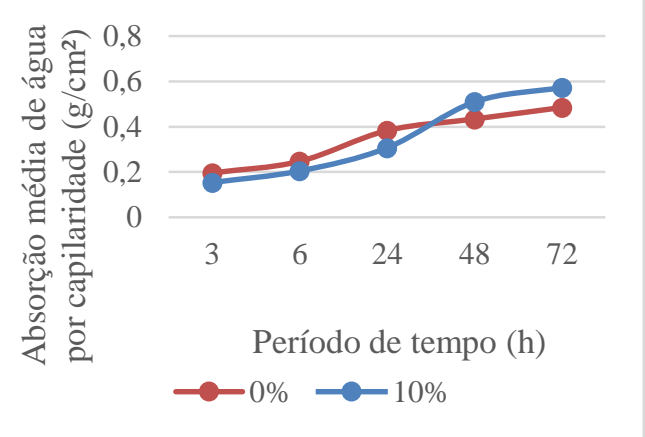

(b)

Figura 1 - Evolução da absorção média de água por capilaridade ao longo do tempo aos 28 dias: cura exposta (a); cura úmida (b).

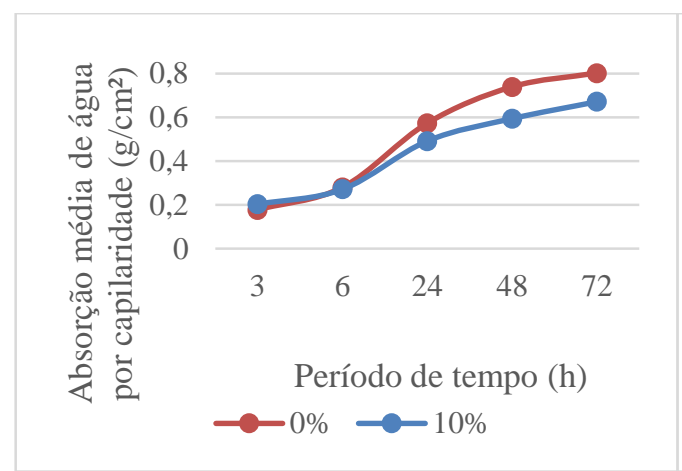

(a)

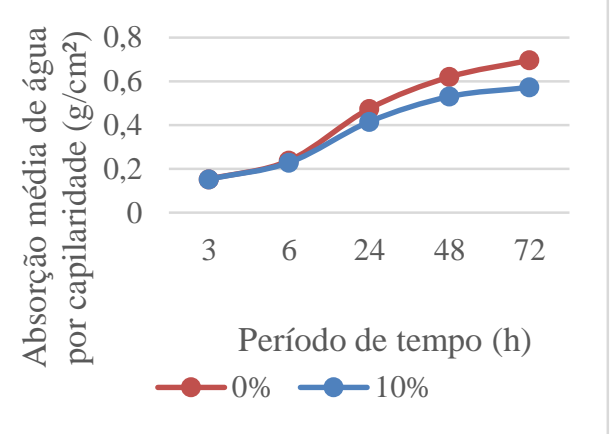

(b)

Figura 2 - Evolução da absorção média de água por capilaridade ao longo do tempo aos 63 dias: cura exposta (a); cura úmida (b).

Como pode-se observar em ambas as idades ensaiadas, os CPs que passaram pelo processo de cura úmida obtiveram um menor valor de absorção, independente do teor de substituição. Também pode-se verificar que no ensaio aos 63 dias demonstrado na Figura 2 em ambas as curas houve uma menor absorção nos CPs com substituição de $10 \%$. Após passarem por tratamento estatístico os dados foram submetidos ao método de análise de variância (ANOVA), com a intenção de analisar se os fatores de controle promoveram algum efeito significativo na variável de resposta (absorção de água por capilaridade). O efeito isolado do tipo de cura e a idade influenciaram significativamente nos resultados dos ensaios, bem como o efeito combinado dessas duas variáveis. Na Figura 3 (a) pode-se observar o efeito isolado do tipo de cura na absorção de água por capilaridade. Percebe-se que ocorreu uma significativa diminuição da absorção de água por capilaridade nas combinações C3 e C4, que passaram pelo processo de cura úmida. A Figura 3 (b) representa o efeito isolado da idade no resultado de absorção de água por capilaridade. Observa-se que houve um aumento considerável na absorção dos CPs ensaiados aos 63 dias. 


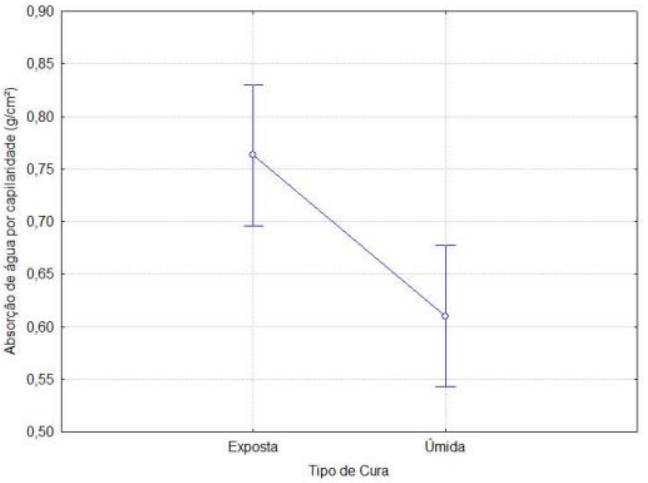

a)

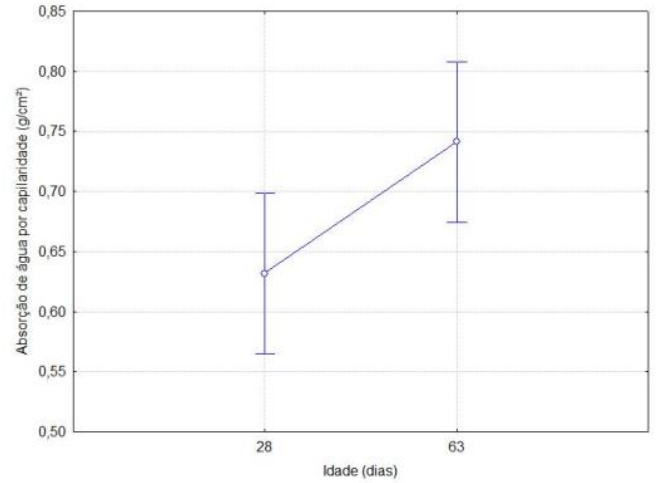

b)

Figura 3 - Efeito isolado do tipo de cura (a) e da idade (b) na absorção de água por capilaridade.

A Figura 4 demonstra o efeito da interação do tipo de cura combinado com a idade na determinação da absorção de água por ascensão capilar, onde observa-se que, para cura exposta a absorção permaneceu igual para as duas idades ensaiadas. Em contrapartida, para o processo de cura úmida ocorreu um considerável aumento na absorção de água para os CPs ensaiados aos 63 dias.

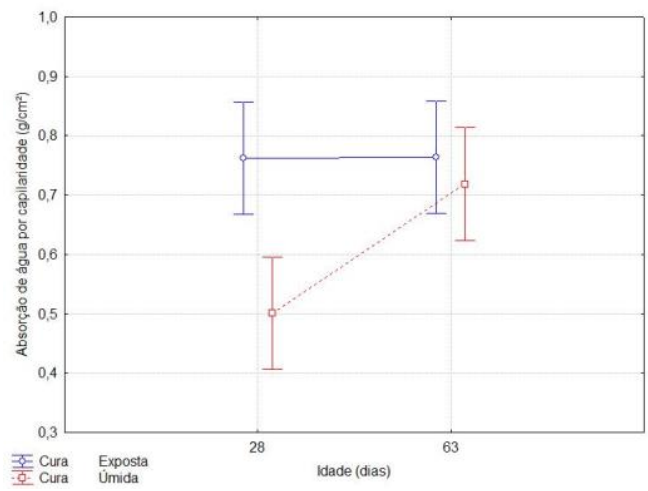

Figura 4 - Efeito combinado da interação tipo de cura x idade na absorção de água por capilaridade.

Analisando a Figura 4, é possivel perceber o aumento de absorção para a cura úmida este fato pode ter como explicação as adições minerais, tais como o MAR, que promovem uma diminuição do diâmetro dos poros do concreto implicando em uma maior sucção de água, mas isso não significa necessariamente que existe uma porosidade ou permeabilidade maior no concreto, tendo em vista que o concreto pode estar expressando uma capacidade maior de sucção de água por força dos capilares com menor diâmetro (TEODORO, 2016).

\subsection{Resistência à compressão uniaxial}

Os ensaios de resistência à compressão uniaxial fornecem um dos principais dados para caracterização de um concreto, que se refere a capacidade de um elemento resistir aos esforços até sua ruptura. Estes ensaios foram executados em conformidade com a NBR 5739 (ABNT, 2018).

Após a obtenção dos resultados, observou-se no geral que houve uma pequena redução de resistência nos CPs com substituição de $10 \%$. Outro aspecto que pode ser observado é o considerável aumento de resistência nos CPs rompidos aos 63 dias. Estes dados podem ser melhor observados na Figura 5. 


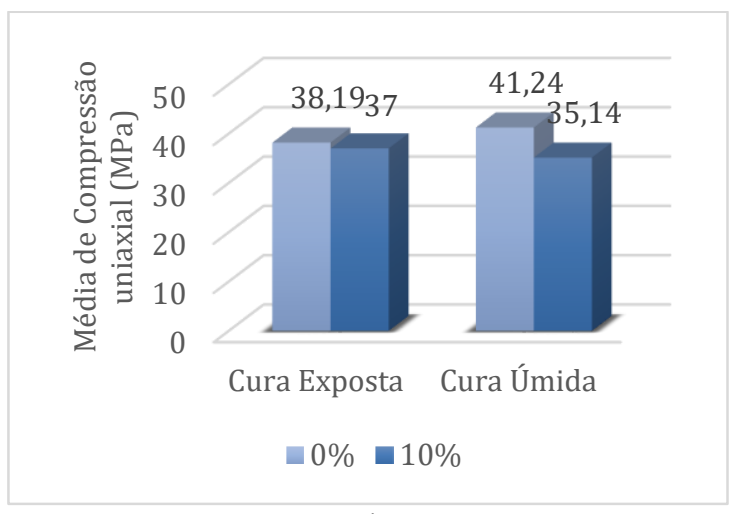

a)

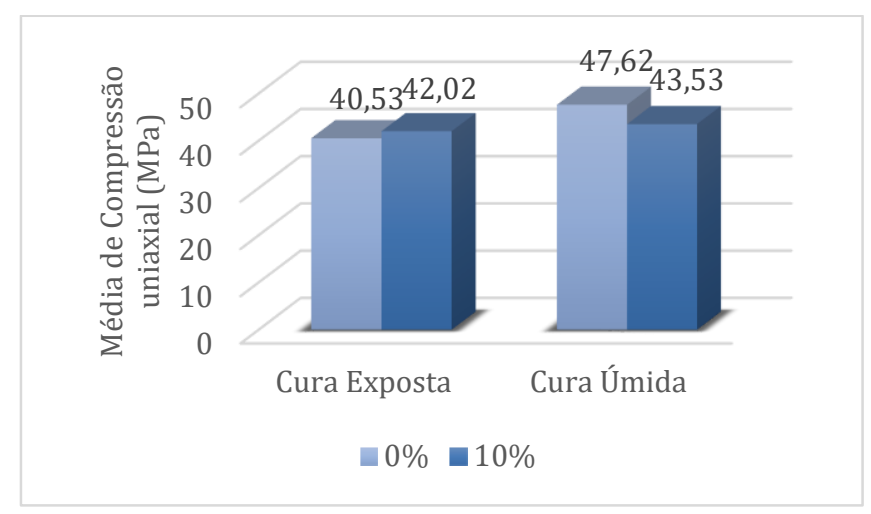

b)

Figura 5 - Resistência à compressão uniaxial aos 28 dias (a) e 63 dias (b).

Em análise estatística dos dados o efeito isolado do teor de substituição, tipo de cura e a idade influenciaram significativamente nos resultados dos ensaios, bem como o efeito combinado do teor de substituição $x$ tipo de cura e da combinação do tipo de cura x idade. É demonstrado na Figura 6 o efeito isolado do teor de substituição no ensaio de compressão uniaxial. Observa-se uma pequena redução da resistência à compressão para os CPs com substituição de $10 \%$ do cimento CPV-ARI por MAR.

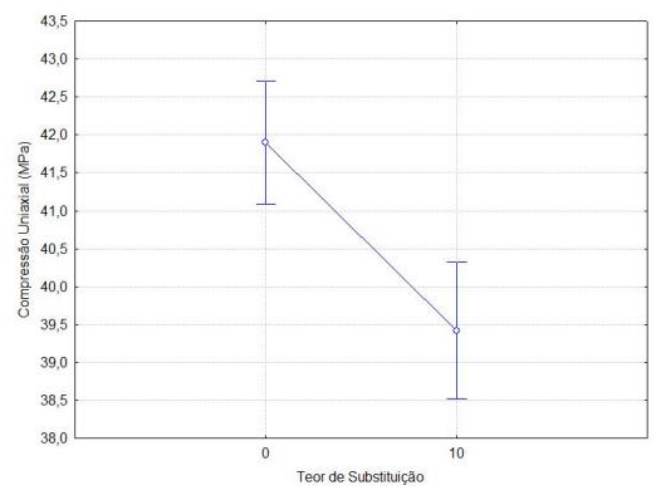

Figura 6 - Efeito isolado do teor de substituição na resistência à compressão uniaxial.

Existe uma relação diretamente proporcional entre o teor de substituição e a resistência à compressão uniaxial, mas os resultados não corroboram com os encontrados por Caldarone et al. (1994), o qual adotou teores de substituição de 5 e $10 \%$.

Pode-se observar também que houve um pequeno aumento na resistência à compressão dos CPs que passaram pelo processo de cura úmida, que explica-se pelo fato deste processo propiciar uma redução significativa na taxa de absorção de água por capilaridade, bem como, o aumento de resistência logo nos primeiros dias. Outro aspecto que pode ser considerado, é que concretos com adição mineral são mais suscetíveis ao efeito das condições de cura do que os concretos com cimento Portland comum, devido a produção de $\mathrm{CH}$ no processo de hidratação do cimento, proveniente das reações com a pozolana, que formam assim produtos de hidratação secundários (MEHTA; MONTEIRO, 2014). 


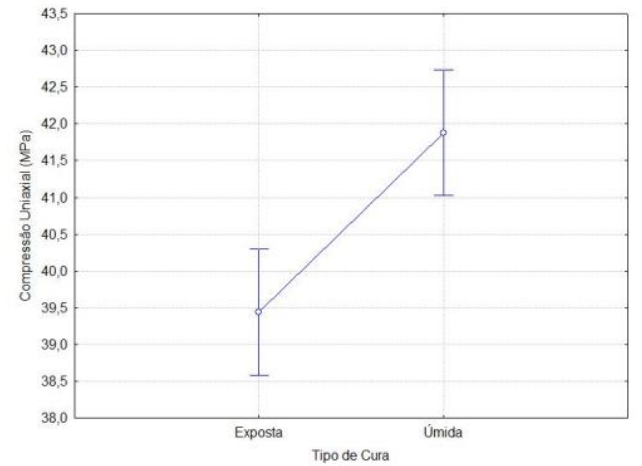

a)

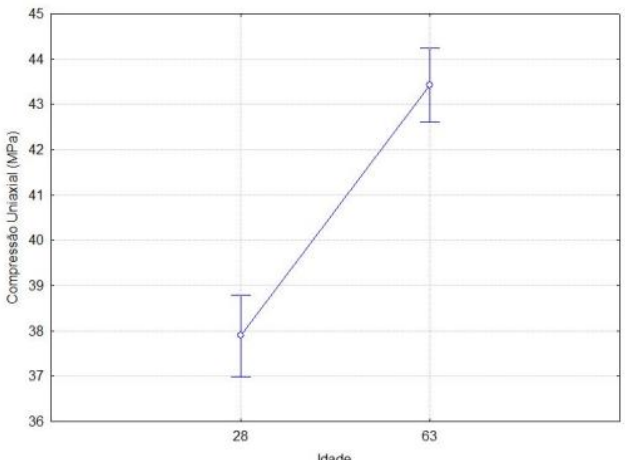

b)

Figura 7 - Efeito isolado do tipo de cura (a) e da idade (b) na resistência à compressão uniaxial.

O efeito isolado que mais influenciou no valor de resistência à compressão uniaxial foi a idade dos ensaios. Esse ganho de resistência aos 63 dias ocorreu em ambas as substituições, mas em proporções maiores nos CPs com substituição de $10 \%$ do cimento Portland por MAR.

Os resultados obtidos neste ensaio foram inferiores aos obtidos nos trabalhos utilizados como referência, onde Souza (2003) obteve uma eficiência aproximada entre $4 \%$ e $22 \%$ em relação ao concreto referência, e justifica que este comportamento ocorreu pelo fato que em seu experimento, nas maiores relações (a/c+MAR), tem-se maior porosidade, ocasionando assim maior eficiência do efeito pozolânico pelo preenchimento dos vazios da mistura, bem como efeito filer.

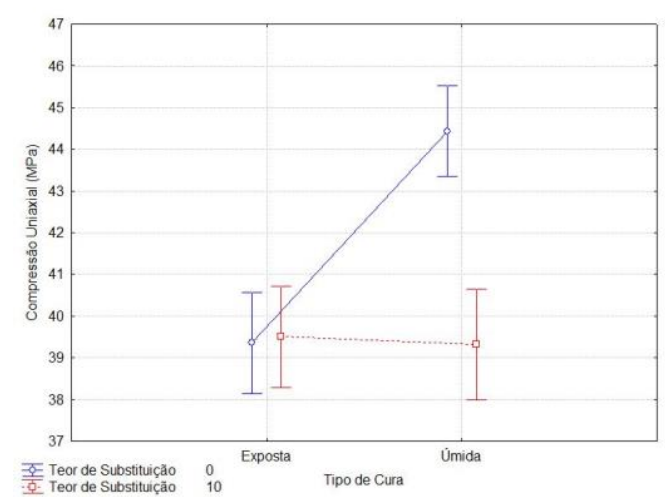

a)

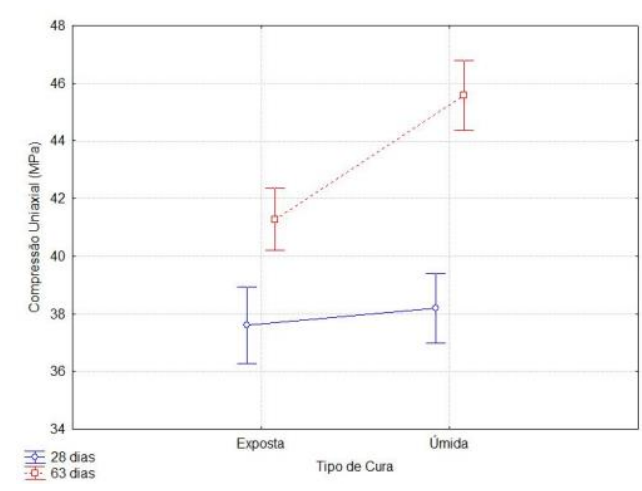

b)

Figura 8 - Efeito combinado do teor de substituição x tipo de cura (a) e idade x tipo de cura (b) na resistência à compressão uniaxial.

A partir da análise da Figura 8 (b) observa-se que os ensaios realizados aos 63 dias obtiveram melhores resultados de compressão em ambas as curas comparado aos 28 dias. Outro aspecto que pode ser observado é que em ambas as idades ensaiadas o processo de cura úmida proporcionou um ganho de resistência em relação a cura exposta, cerca de $10 \%$ para os 63 dias e aproximadamente $1 \%$ aos 28 dias.

\section{Conclusões}

Os concretos produzidos com substituição parcial de $10 \%$ do cimento Portland CPV-ARI por MAR apresentaram, para o ensaio de absorção de água por capilaridade, resultados significativamente menores os 63 dias, principalmente para os CPs que passaram pelo processo de cura úmida, tendo em vista que o alto teor de a/c combinado com a capacidade de adsorção do MAR resultou em uma menor absorção de água por capilaridade.

Análise da infuência do uso do metacaulim de alta reatividade (MAR) nas propriedades mecânicas de concretos autoadensáveis (CAA) 
Observou-se também um pequeno decréscimo na resistência a compressão dos concretos que possuíam 10\% de substituição do cimento Portland CPV-ARI por MAR. Pode-se inferir que estas diferenças provem da dosagem do concreto, variação das características físicas e químicas do MAR. Essas diferenças entre resultados que não comprometeram confiabilidade do trabalho. Algumas variáveis demonstraram-se importantes para o ensaio de compressão uniaxial, uma delas é a cura úmida, que analisando seu efeito isolado constatou-se que ela proporcionou um aumento considerável da resistência, fato de consenso no meio acadêmico. Outra variável que demonstrou efeito significativo nos resultados de compressão uniaxial foi a idade de execução dos ensaios. Conclui-se que a utilização do MAR em substituição parcial do cimento Portland proporciona menor consumo de cimento, sem alterar consideravelmente as propriedades físicas.

\section{Agradecimento}

Os autores agradecem a Universidade Regional Integrada - URI e o apoio financeiro provido pelas bolsas da CAPES.

\section{Referências Bibliográficas}

ASSOCIAÇÃO BRASILEIRA DE NORMAS TÉCNICAS. NBR 5739: Concreto:Ensaio de compressão em corpos-de-prova cilíndricos. Rio de Janeiro, 2007.

ASSOCIAÇÃO BRASILEIRA DE NORMAS TÉCNICAS. NBR 12653: Materiais pozolânicos - Requisitos. Rio de Janeiro, 2015.

ASSOCIAÇÃO BRASILEIRA DE NORMAS TÉCNICAS. NBR 15894/1: Metacaulim para uso com cimento Portland em concreto, argamassa e pasta. Parte 1: Requisitos. Rio de Janeiro, 2010.

Caldarone, M.A.; Gruber, K. A.; Burg, R.G. High-reactivity Metakaolin: A New Generation Mineral Admixture. Concrete International, v.16, n.11, 1994. p. 37-40. Disponível em: <https://www.concrete.org/>. Acesso em: 15 abr. 2019.

Coppola, L. Self-compacting concrete. In: Concrete Technology, p. 42-47, 2000. Disponível em: <https://www.sciencedirect.com/science/article/pii/S0008884699002306>. Acesso em: 29 abr. 2019.

Dal Molin, D. C. C. Contribuição ao estudo das propriedades mecânicas dos concretos de alta resistência com e sem adição de microssílica. 1995, 186p. Tese (Doutorado em Engenharia) - Escola Politécnica da Universidade de São Paulo, São Paulo.

Duarte, S.G.G.R. et al. Adição de sílica ativa e do metacaulim no concreto para avaliação da corrosão por íons cloreto. In: CONFERÊNCIA NACIONAL DE PATOLOGIAS E RECUPERAÇÃO DE ESTRUTURAS, V.1 N.1., 2017, Recife. Anais [...]. Universidade de Pernambuco (UPE): Revistas Poli, 2017.

Gardolinski, J.E.F.C. Composto de intercalação derivados da caulinita. 201 f. Dissertação de mestrado - Pós-Graduação em Engenharias, Universidade Federam do Paraná, Curitiba, 2001.

Gomes, P.C.C. Optimization and characterization of high-strength self-compactig concrete. Tese de doutorado, Barcelona, 2002.

Helene, P.; Terzian, P. R. Manual de Dosagem e Controle do Concreto. São Paulo: PINI, 1992. 350 p.

Lacerda, C.S.; Helene, P.R. (2014). Estudo da Influência da Susbtituição de Cimento Portland por Metacaulim em Concretos. Boletim Técnico da Escola Politécnica da USP, Departamento de Engeharia de Cosntrução Civil, São Paulo, 2005.

Mehta, P.K.; Monteiro, P.J.M. Concreto: estrutura, propriedades e materiais. São Paulo: PINI, 1994.

Rocha, G.G.N. Caracterização microestrutural do metacaulim de alta reatividade. 2005. 96 f. Dissertação (Mestrado) Curso de Engenharia Metalúrgica e de Minas, Universidade Federal de Minas Gerais, Belo Horizonte, 2005.

Souza, P.S.L. Verificação da influência do uso de metacaulim de alta reatividade nas propriedades mecânicas do concreto de alta resistência. 203 f. Tese (Doutorado) - Curso de Engenharia Civil, Universidade Federal do Rio Grande do Sul, Porto Alegre, 2003.

Teodoro, R. Avaliação das características de diferentes metacaulins e sua influência na estrutura interna do concreto e em propriedades ligadas à durabilidade. 2016. 193 f. Dissertação (Mestrado) - Curso de Engenharia Civil, Geotecnia, Estrutura e Construção Civil, Universidade Federal de Goiás, Goiânia, 2016. 